\title{
Analisis Kandungan Silikon (Si) pada Batubara PT. Tambang Bukit Tambi Provinsi Jambi
}

\section{Analysis Of Silicone (Si) in Coal of PT. Tambang Bukit Tambi Jambi Province}

\author{
Heriyanti $^{*}$, Winda Mustika Sari ${ }^{2}$, Sutrisno ${ }^{2}$, Rayandra Asyhar ${ }^{2}$ \\ ${ }^{1}$ Program Studi DIII Kimia Industri, Universitas Jambi, Indonesia \\ ${ }^{2}$ Program Studi Kimia, Universitas Jambi, Indonesia
}

\section{A B S T R A K}

Batubara merupakan komoditas hasil tambang dan merupakan produk andalan di Provinsi Jambi. Batubara merupakan endapan sedimen yang terdiri dari komponen organik dan anorganik, yang mengandung jenis-jenis mineral yang terikat didalamnya, yaitu diantaranya $\mathrm{C}$, Si dan Al. Tujuan penelitian ini adalah melakukan analisis kandungan silikon untuk menentukan jenis batubara yang dihasilkan oleh PT. Tambang Bukit Tambi. Metode yang dilakukan adalah dengan mengekstraksi batubara menggunakan $\mathrm{NaOH} 3 \mathrm{M}$ dan $\mathrm{HCl} 1 \mathrm{M}$ dan dilanjutkan engan metode metalotermis. Hasil ekstraksi diperoleh silika adalah massa rata-rata sebesar 4,89 gram dengan persentasi kadar 46,57\%. Kadar silikon yang didapatkan dari hasil metalotermis yang dianalisis menggunakan AAS adalah sebesar 7,23\%. Berdasarkan kadar silikon, maka batubara PT. Tambang Bukit Tambi dikategorikan dalam jenis batubara sub bituminus.

\begin{abstract}
A B S T R A C T
Coal is the result of mining and is a mainstay commodity in Jambi Province. Coal is a sedimentary deposit consisting of organic and inorganic components, which contain various types of minerals bound, including $C$, Si and Al. The purpose of this study is to analyze the silicon content to determine the type of coal produced by PT. Tambang Bukit Tambi. The method used is by extracting coal using NaOH $3 M$ and $\mathrm{HCl} 1 \mathrm{M}$ followed by the metallothermic method. The result of extraction obtained by silica is an average mass of 4.89 grams with a percentage level of 46.57\%. The silicon content obtained from metallothermal results analyzed using AAS was 7.23\%. Based on silicon content, PT. The Bukit Tambi mine is categorized in the type of sub bituminous coal.
\end{abstract}

Kata kunci : batubara, metode metalotermis, silikon

Keyword : coal, metallothermic method, silicon

I N F O A R T I K E L

Received: 05 Oct 2019;

Revised:14 Nov 2019;

* coresponding author: heriyanti@unja.ac.id

Accepted: 04 Des 2019

DOI: https://doi.org/10.22437/jisic.v11i2.7761 


\section{PENDAHULUAN}

Sumber daya batubara di Sumatera saat ini mencapai $64.592,37$ juta ton, dengan cadangan batubara sebesar 14.799,99 juta ton yang kualitasnya bervariasi, mulai dari batubara kalori tinggi hingga batubara kalori rendah. Pada beberapa tempat, telah banyak dilakukan penambangan endapan batubara kalori rendah, baik dalam skala besar maupun kecil (Tim Survei Terpadu, 2011). Batubara di Provinsi Jambi merupakan komoditas hasil tambang dan produk andalan dengan deposit sekitar 2,75\% dari total batubara Nasional. Dari sekitar 400 juta ton deposit yang ada, $60 \%$ diantaranya merupakan batubara peringkat rendah dengan nilai kalori antara $4.500 \mathrm{~s} / \mathrm{d} 5.600$ k.kal/kg dan kadar air 35\% (Faizar, 2009). Oleh karena itu beberapa perusahaan di Provinsi Jambi banyak yang melakukan kegiatan penambangan batubara, khususnya PT. Tambang Bukit Tambi yang berlokasi di Desa Padang Kelapo Kecamatan Marosebo Kabupaten Batanghari, Provinsi Jambi.

Batubara merupakan endapan sedimen yang terdiri dari komponen organik dan anorganik, yang mengandung jenis-jenis mineral yang terikat didalamnya, yaitu diantaranya karbon (C), silikon (Si), aluminium (Al), magnesium (Mg), dan kalsium $(\mathrm{Ca})$. Beberapa mineral yang terdapat pada batubara unsur silikon (Si) merupakan salah satu mineral yang memiliki komposisi cukup tinggi, silikon pada batubara terdapat dalam bentuk mineral oksidanya yaitu silika $\left(\mathrm{SiO}_{2}\right)$ (Sugiarto, et al 2015). Silikon merupakan senyawa yang bersifat metalloid dan merupakan unsur yang tidak beracun dan memiliki banyak manfaat bagi kehidupan salah satunya yaitu pada perangkat keras komputer dan industri mikroelektrokimia, manfaat silikon dalam bidang industri yaitu dapat digunakan sebagai salah satu pencegah korosi pada campuran baja. Adanya unsur mineral yang tinggi pada batubara dapat mempengaruhi daya pembakaran batubara tersebut dan menurut Yatish (2015) adanya silikon (Si) pada batubara memiliki efek yang menguntungkan pada retensi sulfur di suhu tinggi. Kadar silikon (Si) pada batubara ini dapat diketahui dengan cara mengisolasi silikon ( $\mathrm{Si})$ dari ekstrak silika $\left(\mathrm{SiO}_{2}\right)$ batubara dan diukur menggunakan instrumen. Dari penelitian Sugiarto, et al (2015), isolasi silikon (Si) dapat dilakukan metode metalotermis menggunakan reduktor aluminium dengan hasil rendemen silika hasil ektraksi sebesar 39,078-47,58\%, silikon hasil metalotermis pada penelitian ini berupa silikon kasar. Melihat dari produksi dan pemanfaatan batubara yang cukup besar di Provinsi Jambi serta adanya pengaruh mineral terhadap kualitas batubara, maka perlu dilakukan beberapa analisis untuk dapat menentukan kualitas pada batubara yang dihasilkan dari penambangan oleh PT. Tambang Bukit Tambi.

Menurut Billah (2010), penentuan kualitas batubara dapat ditentukan oleh suhu serta lama waktu pembentukannya, maka dari itu suhu memiliki peranan penting dalam penentuan kualitas batubara. Penilaian kualitas batubara juga ditentukan oleh beberapa parameter yang terkandung dalam batubara dan dapat ditentukan dari sejumlah analisis di laboratorium, salah satunya dengan Analisis mikro. Analisis mikro merupakan penentuan unsur penyusun suatu senyawa yang dilakukan dengan menggunakan microelemental analyzer, analisis ini sangat bermanfaat untuk mengetahui kemurnian suatu sampel.

\section{METODE PENELITIAN}

\section{Bahan dan Peralatan}

Bahan yang digunakan dalam penelitian ini adalah batubara yang berasal dari PT Tambang Bukit Tambi, HCl (Merck 37\%), HF (Merck 48\%), $\mathrm{HClO}_{4}$ (Merck 60$70 \%$ ), $\mathrm{NaOH}$ (Merck), $\mathrm{HNO}_{3}$ (Merck 65\%), $\mathrm{H}_{2} \mathrm{SO}_{4}$ (Merck 98\%), serbuk aluminium (Merck) dan aquadest.

Alat yang akan digunakan untuk mendukung penelitian ini diantaranya adalah seperangkat alat gelas, termometer, grinder, ayakan, oven (CKIC 5E-DHG), furnace (Changsa Kaiyuan), Atomic Adsorption Spectrophotometer (AAS). 


\section{Preparasi Sampel}

Batubara dihancurkan menggunakan grinder FIRTSCH pulverisette-16 dan diayak dengan ukuran 100 Mesh. Sampel batubara sebanyak $50 \mathrm{~g}$ direndam dalam air panas selama 2 jam (Retnosari, 2013).

\section{Leaching}

Sampel batubara sebanyak 25 gram dimasukkan ke dalam labu bulat dan tambah

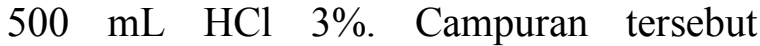
direfluks selama 2 jam, setelah itu disaring dan residu dicuci dengan aquadest panas hingga netral. Residu dikeringkan dalam oven pada suhu $100^{\circ} \mathrm{C}$ (Okutani, 2009).

\section{Ekstraksi Silika batubara}

Sampel batubara hasil leaching direndam dalam larutan $\mathrm{NaOH} \quad 3 \quad$ M kemudian dipanaskan hingga mendidih yang disertai pengadukan dengan kecepatan 150 rpm selama 120 menit. Larutan tersebut disaring dan filtratnya ditampung dalam gelas beaker. Silika diendapkan dengan cara menambah larutan $\mathrm{HCl} 1 \mathrm{M}$ ke dalam filtrat secara bertahap hingga rentang $\mathrm{pH}$ 6,5-7. Endapan dipisahkan dan dibilas menggunakan aquadest untuk mengilangkan kelebihan asam. Silika yang diperoleh selanjutnya dikeringkan dalam oven pada suhu $110^{\circ} \mathrm{C}$ selama 6 jam untuk menghilangkan air (Retnosari, 2013).

\section{Karakterisasi Silika Hasil Ekstraksi Dengan Metode Gravimetri}

Silika dilarutkan dengan aquadest, $\mathrm{HNO}_{3}$ p.a, $\mathrm{HClO}_{4}$ p.a, kemudian dipanaskan sampai keluar uap putih. Selanjutnya larutan disaring dengan kertas saring Whattman nomor 41. Kertas saring dan residu dicuci dengan air panas sebanyak 15 kali. Kemudian residu dan kertas saring dimasukkan kedalam cawan platina, setelah itu dipanaskan dan dibakar diatas nyala gas sampai terbentuk abu kemudian diijarkan pada furnace dengan suhu $1000^{\circ} \mathrm{C}$ selama 30 menit. Setelah itu didinginkan dalam desikator vakum 20 menit kemudian timbang. Selanjutnya residu dalam platina dilarutkan dengan sedikit air, ditambahkan 1-2 tetes $\mathrm{H}_{2} \mathrm{SO}_{4}$ dan $5 \mathrm{HF}$, diuapkan sampai kering diatas plat pemanas dan dipijarkan pada furnace dengan suhu $1000^{\circ} \mathrm{C}$ selama 2 menit. Kemudian didinginkan dalam desikator vakum 20 menit dan hasilnya ditimbang (Retnosari, 2013).

\section{Isolasi Silikon Dari Silika Batubara \\ Dengan Metode Metalotermis}

Silika sebanyak 1,5 gram dan 0,9 gram aluminium ditempatkan dalam cawan porselin. Campuran tersebut dipanaskan dalam furnace pada suhu $850^{\circ} \mathrm{C}$ selama 3 jam. Campuran yang telah dipanaskan kemudian didinginkan dan dilakukan prosedur pemisahan serta analisis silikon hasil metalotermis (Andarini, 2018).

\section{Pemisahan Campuran Silikon dan}

\section{Alumina}

Pemisahan campuran atau reduksi alumina untuk mendapatkan silikon dilakukan dengan metode pengasaman menggunakan larutan $\mathrm{HCl} 3 \mathrm{M}$, larutan $\mathrm{HCl}$ tersebut dituangkan secara perlahan pada produk reaksi metalotermis kemudian dipanaskan pada suhu $70^{\circ} \mathrm{C}$ selama 60 menit. Prosedur tersebut diulang 3 kali, tahapan selanjutnya yaitu campuran dibilas dengan aquadest panas berulang kali hingga netral, setelah itu campuran difiltrasi dan dikeringkan dalam oven $60^{\circ} \mathrm{C}$ selama 60 menit. Padatan yang telah dikeringkan dibiarkan selama 12 jam dan ditimbang hingga massanya konstan (Armaina, 2013).

\section{Analisis Silikon Hasil Metalotermis}

Analisis silikon hasil metalotermis dilakukan secara kuantitatif dengan menggunakan AAS.

\section{HASIL DAN PEMBAHASAN}

Dalam penentuan kadar Silikon, proses ekstraksi ini perlu dilakukan, karena pada batubara kandungan mineral berupa 
silika $\left(\mathrm{SiO}_{2}\right)$ saling berikatan dengan Alumina $\left(\mathrm{Al}_{2} \mathrm{O}_{3}\right)$ dalam bentuk Silikat Alumina, maka dari itu diperlukan pemisahan Silika dan Alumina untuk dapat menentukan kadar silikon menggunakan AAS.

Ekstraksi yang digunakan pada penelitian ini merupakan jenis ekstraksi padat-cair. Ekstraksi padat-cair merupakan suatu proses yang melibatkan perpindahan massa antar fasa, pada penelitian ini adapun yang berperan sebagai fasa padat adalah sampel batubara dan $\mathrm{NaOH}$ digunakan sebagai ekstraktan. Pada ekstraksi padatcair, ketika bahan ekstraksi dicampur dengan ekstraktan maka ekstraktan akan bereaksi dengan bahan padat membentuk ekstrak. Dalam proses ekstraksi padat-cair diperlukan kontak yang sangat lama antara ekstraktan dan padatan.

Langkah awal yang dilakukan pada penelitian ini adalah melakukan preparasi sampel, yaitu 50 gram batubara direndam dalam air panas selama 2 jam untuk mengekstrak bahan-bahan organik larut air berupa karbon agar tidak mengganggu pada saat proses ektraksi silika, penggunaan air panas dimaksudkan untuk mempercepat terekstraknya karbon karena suhu adalah salah satu faktor yang berpengaruh dalam proses ekstraksi, yaitu semakin tinggi suhu maka semakin banyak karbon yang akan terekstrak (Retnosari, 2013). Setelah dilakukan perendaman dengan air panas dan dikeringkan, selanjutnya dilakukan prosedur leaching (pengasaman), proses ini dilakukan bertujuan untuk menghilangkan zat-zat menguap. Proses leaching ini juga dapat meningkatkan kuantitas silika hasil ekstraksi dimana pada penelitian yang dilakukan oleh Retnosari (2013) tanpa melakukan metode leaching didapatkan kadar silika sebanyak 1,2781 gram sedangkan penelitian yang dilakukan oleh Sugiarto, et al (2015) kadar silika yang didapatkan dengan adanya metode leaching adalah sebesar 3,598 gram.

\section{Ekstraksi Silika}

Proses ini dilakukan dengan menggunakan ekstrakstan berupa $\mathrm{NaOH}$. $\mathrm{NaOH}$ merupakan senyawa yang bersifat basa yaitu bila dilarutkan dalam air akan memisahkan dan melepaskan ion $\mathrm{OH}^{-}$. Pemilihan penggunaan $\mathrm{NaOH}$ dalam penelitian ini dikarenakan silika dapat bereaksi dengan basa terutama basa kuat seperti hidroksi alkali. Langkah awal yang dilakukan pada proses ekstraksi silika ini adalah 25 gram batubara direndam dalam $100 \mathrm{~mL}$ larutan $\mathrm{NaOH} 3 \mathrm{M}$ yang kemudian dipanaskan hingga mendidih disertai pengadukan selama 1 jam. Pemanasan dilakukan untuk mempercepat laju reaksi, karena kenaikan suhu akan meningkatkan jumlah silika yang larut ke dalam ekstraktan. Secara umum pengadukan dilakukan untuk mendistribusikan suhu agar merata dan mempercepat kontak antara pelarut dengan zat terlarut. Pada proses ektraksi ini pun pengadukan juga bertujuan untuk mengurangi pengendapan (Kurniati, 2009). Reaksi yang terjadi yaitu:

$$
\begin{gathered}
\mathrm{SiO}_{2}(\mathrm{~s})+2 \mathrm{NaOH}(\mathrm{aq}) \longrightarrow \\
\mathrm{Na}_{2} \mathrm{SiO}_{3}(\mathrm{aq})+\mathrm{H}_{2} \mathrm{O}(\mathrm{aq})
\end{gathered}
$$

Larutan disaring untuk memisahkan filtrat dan residu. Filtrat yang diperoleh merupakan larutan natrium silikat yang kemudian ditambahkan larutan $\mathrm{HCl} 1 \mathrm{M}$ hingga terbentuk endapan yang berada pada rentang $\mathrm{pH}$ 6,5-7, karena endapan silika akan mulai terbentuk pada $\mathrm{pH}$ dibawah 10 . Menurut Suka et al (2008), pemilihan nilai $\mathrm{pH}$ ini didasarkan pada sifat sifat silika yang tidak larut dalam media dengan suasana netral, sehingga pada kondisi ini pengendapan silika diharapkan berlangsung secara optimal. Penambahan larutan $\mathrm{HCl}$ berfungsi sebagai asam kuat yang akan menyebabkan terjadinya pertukaran ion $\mathrm{Na}^{+}$ dan $\mathrm{H}^{+}$menghasilkan suatu padatan berbentuk gel yang akhirnya memisahkan partikel dari silika yang terikat dengan molekul air yaitu silika hidrosol atau asam silikat $\left(\mathrm{H}_{2} \mathrm{SiO}_{3}\right)$. Reaksinya yaitu:

$$
\begin{gathered}
\mathrm{Na}_{2} \mathrm{SiO}_{3}(\mathrm{aq})+2 \mathrm{HCl}(\mathrm{aq}) \longrightarrow \\
\mathrm{H}_{2} \mathrm{SiO}_{3}(\mathrm{~s})+2 \mathrm{NaCl}(\mathrm{aq})
\end{gathered}
$$

Selanjutnya dilakukan penyaringan terhadap endapan dan filtrat, dimana endapan yang didapat berupa asam silikat 
$\left(\mathrm{H}_{2} \mathrm{SiO}_{3}\right)$ dan filtratnya berupa $\mathrm{NaCl}$, endapan yang didapatkan dicuci dengan aquades panas untuk menghilangkan kelebihan asam dan selanjutnya endapan yang diperoleh dikeringkan dalam oven pada suhu $110^{\circ} \mathrm{C}$ selama 6 jam, pemanasan pada suhu ini mengakibatkan dehidrasi silika hidrosol sehingga terbentuk silika gel $\left(\mathrm{SiO}_{2} \cdot \mathrm{H}_{2} \mathrm{O}\right)$ yang kemudian dihaluskan untuk mendapatkan bubuk silika (Lubis, 2009). Adapun reaksinya yaitu:

$$
\mathrm{H}_{2} \mathrm{SiO}_{3}(\mathrm{~s}) \longrightarrow \mathrm{SiO}_{2}(\mathrm{~s})+\mathrm{H}_{2} \mathrm{O}(\mathrm{aq})
$$

Bubuk silika yang didapatkan dari hasil ekstraksi kemudian dilakukan analisis kadarnya menggunakan metode gravimetri. Penentuan kadar ini pertama dilakukan dengan menimbang 0,5 gram sampel yang dibasahkan dengan aquades dan kemudian ditambahkan $\mathrm{HNO}_{3}$ p.a dan $\mathrm{HClO}_{4}$ p.a. selanjutnya larutan tersebut dipanaskan hingga keluar uap putih, uap putih tersebut merupak oksida-oksida yang masih terjebak dalam pertumbuhan kristal silika. Penambahan kedua asam kuat tersebut dilakukan agar Si dapat terpisah dengan Al, proses ini menghasilkan endapan silika dan larutan berwarna kekuningan yang mengandung pengotor yang terdapat pada endapan silika hasil ekstraksi.

Selanjutnya, larutan didinginkan dan kemudian ditambahkan aquades sebanyak $50 \mathrm{~mL}$ dan kemudian dipanaskan kembali hingga garam-garam yang terbentuk larut. Setelah itu disaring menggunakan kertas saring dan selanjutnya residu dipijarkan ke dalam furnace pada suhu $1000^{\circ} \mathrm{C}$ selama 30 menit, kemudian didinginkan dalam desikator selama 20 menit untuk menghilangkan kandungan uap air lalu kemudian di timbang berat endapan (A). Endapan yang diperoleh kemudian dilarutkan dengan $\mathrm{HF}$ dan $\mathrm{H}_{2} \mathrm{SO}_{4}$ kemudian diuapkan hingga kering dan dipijarkan kembali ke dalam furnace pada suhu $1000^{\circ} \mathrm{C}$ selama 2 menit. Kemudian di masukkan kembali kedalam desikator selama 20 menit dan ditimbang (B). Pada penelitian ini diperoleh massa silika rata-rata sebesar 4,89 gram dengan persentasi kadar 46,57\%. Berdasarkan penelitian yang dilakukan
Sugiarto, et al (2015) jika silika terekstrak sempurna, maka akan didapatkan massa silika sebanyak 7,5625-9,2075 gram.

\section{Isolasi Silikon}

Selanjutnya dilakukan pemisahan antara Silika dan Alumina yang dapat dilakukan dengan menggunakan metode metalotermal. Pada metode ini 1,5 gram silika hasil ekstraksi dicampurkan dengan 0,9 gram aluminium yang kemudian dipijarkan pada furnace dengan suhu $850^{\circ} \mathrm{C}$ selama 3 jam. Pencampuran ini dilakukan berdasarkan reaksi berikut:

$$
3 \mathrm{SiO}_{2}(\mathrm{~s})+4 \mathrm{Al}(\mathrm{s}) \longrightarrow 2 \mathrm{Si}(\mathrm{s})+3 \mathrm{Al}_{2} \mathrm{O}_{3}(\mathrm{~s})
$$

Berdasarkan penelitian yang dilakukan oleh Sugiarto, et al (2015) suhu $850^{\circ} \mathrm{C}$ merupakan suhu optimum untuk reaksi metalotermis, dan berdasarkan penelitian Subakti (2013) lama waktu optimum yang digunakan untuk reaksi metalotermis adalah 3 jam. Kemudian selanjutnya campuran ini didinginkan dan dilakukan pemisahan dengan melakukan reduksi Alumina menggunakan metode pengasaman menggunakan larutan $\mathrm{HCl} 3 \mathrm{M}$. Larutan tersebut dituangkan secara perlahan pada produk reaksi metalotermis, kemudian diaduk dan dipanaskan selama 1 jam prosedur tersebut diulang sebanyak 3 kali agar alumina diharapkan tereduksi sempurna dengan pelarut berupa $\mathrm{HCl}$, kemudian larutan tersebut disaring. Padatan yang didapatkan kemudian dicuci dengan aquades panas berulang kali hingga netral dan kemudian dikeringkan padatan dalam oven pada suhu $60^{\circ} \mathrm{C}$ selama 1 jam. Hasil reaksi metalotermis ini kemudian diuji menggunakan AAS. Kadar silikon yang didapatkan dari hasil metalotermis sebesar 7,23\%.

Pada analisa AAS sampel yang digunakan harus dalam bentuk larutan maka dari itu silikon hasil metalotermis dilarutkan dalam larutan HF dikarenakan sifat silikon yang tidak reaktif dengan kebanyakan asam dan dalam kondisi normal, tetapi dapat larut 
dalam asam flourida (HF). Reaksinya adalah sebagai berikut:

$$
\begin{gathered}
\mathrm{Si}(\mathrm{s})+6 \mathrm{HF}(\mathrm{aq}) \underset{[\mathrm{SiF} 6]^{2-}(\mathrm{aq})+2 \mathrm{H}^{+}(\mathrm{aq})+2 \mathrm{H} 2(\mathrm{~g})}{\longrightarrow}
\end{gathered}
$$

Kadar silikon hasil metalotermis yang didapatkan menunjukkan bahwa silikon yang didapatkan dari hasil reaksi metalotermis cukup besar yaitu 7,23\% besarnya kadar silikon ini mendekati hasil analisis SEM-EDX dimana pada hasil SEMEDX untuk spot dengan perbesaran $0,2 \mu \mathrm{m}$ diperoleh kadar silikon (Si) pada batubara sebesar 10,97\% (Heriyanti, 2018). Hal ini membuktikan bahwa metode metalotermis cukup efisien digunakan untuk proses isolasi silikon pada batubara, begitu pula dengan hasil ekstraksi dimana kadar silika yang didapatkan pada proses ektraksi cukup besar yaitu 46,57\%. Besarnya kadar silikon (Si) yang didapatkan ini juga dapat mengidentifikasikan bahwa sampel batubara

\section{DAFTAR RUJUKAN}

Andarini, N, Haryati, T., \& Yulianti, R. (2018). Pemurnian silikon (Si) hasil reduksi silika dari fly ash batubara. Berkala Sainstek. 6(1), 49-54

Armaina, R., Mariana. B. M., \& Yudha, A. (2013). Penentuan celah energi (energy gap) silikon hasil reaksi metalotermis aluminium dan silika dari abu sekam padi. Jurnal Prisma Fisika, 1(1), 56-60.

Billah, M. (2010). Peningkatan nilai kalor batubara peringkat rendah dengan menggunakan minyak tanah dan minyak residu. Surabaya : UPN Press

Faizar, F. (2011). Adsorpsi batubara terhadap ion timbal. Sainmatika: Jurnal Sains dan Matematika, 3(1)

Heriyanti, Prendika, W., Asyhar, R., \& Sutrisno. (2018). Thermal behaviour and microanalysis of coal subbituminous. IOP Conf. Series: Materials Science and Engineering 345 yang digunakan termasuk dalam batubara tingkat sub-bituminus.

\section{KESIMPULAN DAN SARAN}

Kadar silikon (Si) yang didapatkan pada batubara PT. Tambang Bukit Tambi menggunakan proses isolasi dengan metode metalotermis ini adalah 6,9\%. Hasil-hasil analisis ini mengindikasikan bahwa sampel batubara yang digunakan merupakan batubara tingkat sub-bituminus.

\section{UCAPAN TERIMA KASIH}

Terima kasih diucapkan pada Lembaga Penelitian dan Pengabdian Masyarakat Universitas Jambi yang telah membiayai penelitian ini melalui Dana DIPA PNBP LPPM Universitas Jambi Tahun Anggaran 2017 Nomor: $\quad$ SP DIPA-042.01.2.400950/2017 tanggal 07 Desember 2016, sesuai dengan Surat Perjanjian Kontrak Penelitian Nomor: 350/UN21.17/PP/2017 Tanggal 31 Mei 2017.

Kurniati, Ely. (2009). Ekstraksi silica white powder dari limbah padat pembangkit listrik tenaga panas bumi dieng. Surabaya : Penerbit UPN Press

Lubis, S. (2009). Preparasi katalis Cu/silika gel dari kristobalit alam sabang serta uji aktivitasnya pada reaksi dehidrogenasi etanol. Jurnal Rekayasa Kimia dan Lingkungan. 7(1), 29-35

Okutani, T. (2009). Utilization of silica in rice hulls as raw materials for silicon semiconductors. Journal of Metals, Materials And Minerals In Japan. 19(2), 51-59.

Retnosari, A. (2013). Ekstraksi dan penentuan kadar silika (SiO2) hasil ekstraksi dari abu terbang (Fly Ash) batubara. Skripsi. Jember: Jurusan Kimia Fakultas MIPA Universitas Jember. 
Subakti, A., Malino, M. B., dan Nurhasanah. 2013. Optimasi kandungan silikon dalam produk reaksi metalotermis silika dari abu sekam padi dan aluminium berdasarkan lama waktu reaksi. Prisma Fisika. 1(2), 1-3

Sugiarto, N., Andarini, dan N., Haryati, T. 2015. Isolasi silikon (Si) dari fly ash batubara dengan metode metalotermis menggunakan reduktor aluminium. Prosiding Seminar Nasional Kimia 2015
Suka, I. G., Simanjuntak, W., Sembiring, S., dan Trisnawati, E. 2008 Karakteristik silika sekam padi dari provinsi lampung yang diperoleh dengan metode ekstraksi. MIPA. 37(1), 47-52

Tim Survei Terpadu, 2011, Penyelidikan terpadu geologi dan geokimia daerah panas bumi sumani kab SolokSumatera Barat. Bandung: Pusat Sumber Daya Geologi.

Yatish Y. S. 2015. Energy and Fuel System Integration. CRC Press: Taylor and Francis Group 